\title{
Some practical points on harm reduction: what to tell your lawmaker and what to tell your brother about Swedish snus
}

\author{
L T Kozlowski, R J O'Connor, B Quinio Edwards
}

Tobacco Control 2003;12:372-373

$F$ or harm reductionists in some countries, smokeless tobacco can be used as a small backfire to help control a larger, more deadly forest fire. For tobacco prohibitionists, smokeless itself is too evil to use even as a tool. For some anti-tobacco scientists, the necessary data may still be lacking. The low tar cigarette disaster seems to have made some policy makers act as if, having been fooled once, their greatest goal is to avoid the shame of being fooled twice.

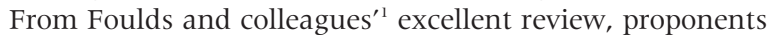
of smokeless tobacco for harm reduction will find useful evidence. Opponents will still question, even if there may be a positive effect in Sweden, whether it can or should be exported. They will disagree with Bates and colleagues ${ }^{2}$ on ending the snuff ban in the European Union. Opponents will proliferate "what ifs" (for example, what if snus is a gateway to cigarettes). They will demand science based regulation (as do harm reductionists). They will say that clinical trials must be completed before taking action (forgetting perhaps that randomised controlled trials were not a requirement to prove cigarettes a cause of premature death).

We doubt that any feasible clinical trial in another country can provide us with better evidence on the possible individual and societal effects of snus. Controlled experiments can be instructive, but the Swedish example is priceless. Physicians and public health professionals are not always the key players in tobacco control-consumers appear to be active participants in the process. The Swedish effects do not appear to have arisen from physicians systematically giving advice to their patients (as a clinical trial might simulate), or from the public health community campaigning to persuade smokers to switch to the safer product, or from manufacturers' advertising.

We agree with the conclusions of this review, ${ }^{1}$ including the special concerns about highly toxic smokeless tobacco in India and Africa. The authors' first conclusion for evidence based product regulation has long been the consensus opinion among those who work on harm reduction. The US Congress has been actively trying to develop a law to regulate tobacco through the Food and Drug Administration. (By publication date, a law may be in place.) From the sidelines, it has become obvious that there are more ways to have legislation make matters worse than better. Some current US legislative issues will be discussed in the first part of this essay.

\section{WHAT TO TELL YOUR LAWMAKER ABOUT SNUS AND HARM REDUCTION We do know how legislation works}

We know that the economic significance of tobacco is so great that the US Congress will not allow legislation leading to the banning of cigarettes. We know any legislation will result from compromises among various powerful factions, only a few of which care a whit about science. Some factions within the health lobby lean only somewhat toward harm reduction, while others are resolved to not even permit loosened restrictions on medicinal nicotine. Many of these factions will have de facto veto power, meaning that no Bill will become law that risks too much change in the status quo. ${ }^{3}$ We know that, at best, science is a gadfly in this process.

We also know the history of Food and Drug Administration in the USA. Apart from the letter of any law, a President can appoint an administrator who neglects some issues and prefers others, and the Congress can also set funding levels that make implementation and enforcement impossible. ${ }^{4}$ We do not expect a panacea from the FDA, but it would be good if a law did more than create "FDA approved" traditional cigarettes.

\section{Snus can help reduce smoking risks for individuals and society}

The evidence from Sweden is persuasive that a certain type of smokeless tobacco is much safer than cigarettes for individuals and probably safer for society. ${ }^{1}$ Some will argue that harm reduction products like snus are unnecessary, since comprehensive prevention and cessation programmes (like those in Massachusetts and California) have driven down smoking rates. But such programmes cannot be expected to eliminate smoking completely. Some smokers will prefer not to stop using nicotine. Some youth will take up smoking no matter what the public health community does (perhaps, to spite it). Harm reduction products like snus offer these individuals an alternative to cigarettes.

\section{Cigarettes are the critical "gateway" to cigarettes}

You, lawmaker, will hear that smokeless tobacco may be a causal gateway to cigarettes (for example, Tomar ${ }^{5}$ ), although there is significant evidence to the contrary. ${ }^{167}$ Note that a dramatic increase in snus use in Sweden did not lead to increased smoking. The major "gateway" to adult cigarette smoking is a cigarette itself. A high risk child would be better off using snus than cigarettes, if the child is determined to use tobacco.

\section{You, lawmaker, should take steps now to stop} misinforming the public; later, don't allow legislation that prohibits comparing the most dangerous products to the least dangerous products

Today, you could have a staffer call the National Clearinghouse for Drug and Alcohol Information (a government agency) and ask that its website stop misinforming the public that smokeless tobacco is just as dangerous as cigarettes. ${ }^{8}$ In general, the message that "no tobacco product is safe" is widely known. Even Philip Morris is now also promoting that "no cigarette is safe" in TV commercials and on its website. ${ }^{9}$ The "not safe" message is easy for agencies and industry lawyers to agree upon. Tackle instead the messages about safer products of greater interest to consumers.

Some proposed legislation ${ }^{3}$ has included a prohibition on comparisons across product types. To provide the most useful information to consumers, information comparing the most 
dangerous products (cigarettes) to much less dangerous products (snus, medicinal nicotine) is an essential component of legislation. By limiting comparative claims only to like products (cigarettes to cigarettes, smokeless to smokeless), the consumer is prevented from understanding where maximal harm reduction lies.

Individuals who do use or who are thinking of using cigarettes have a right to know that smokeless products are safer than cigarettes. ${ }^{10-12}$ Lawmaker, you will have heard the old saw about increased use of a safer product being potentially able to lead to greater risk for society. For large reductions in risk, it is possible, or even likely, that use would not increase to a level that could cause net societal harm. ${ }^{13}$ Snus and medicinal nicotine are so much safer than cigarettes that net societal harm is very unlikely. ${ }^{12}{ }^{13}$ Public health concerns should trump individual rights only when there is clear and convincing evidence of harm to society. Lacking that evidence, individual rights should prevail. ${ }^{12}{ }^{14}$

Some public health advocates have proposed that no harm reduction product shown to increase overall harm to society should be allowed on the market-even if it is shown to reduce individual health risks (for example, Stratton et $a l^{15}$ ). At least one FDA bill ${ }^{3}$ has incorporated such a clause. Philip Morris has prepared a detailed brief arguing that such a clause would be illegal (unconstitutional) on several grounds, one being the principle of free speech. ${ }^{16}$

\section{Don't feel compelled to give FDA regulation over tobacco}

While working toward a law to regulate tobacco, don't forget that you should still support other broad based tobacco control efforts-FDA legislation is not the be-all and end-all of tobacco control. The wrong kind of compromises on legislation could cause more harm than good and could favour the cigarette industry at the expense of the public health. Any attainable law may be worse than no law.

Remember the contributions of snus to reducing smoking caused disease arose outside of FDA-type product regulation.

Imagine a brother who has smoked for years and been trying to quit smoking for years. What follows is what we would tell this hypothetical brother about snus and harm reduction. We feel a special urgency to help him as much as possible.

\section{WHAT TO TELL YOUR BROTHER ABOUT SNUS (IN ORDER)}

1. Quit using any tobacco, if you can. This would provide the greatest health benefit.

2. Try medicinal nicotine. If possible, substitute cleaner forms of nicotine. Don't be afraid of nicotine-be afraid of smoking. 3. Try snus as the Swedes do. Try snus as a complete substitute for smoking and in the way the Swedes do. That Swedish snus is much safer than cigarettes is supported by ample scientific evidence.

- Use a product meeting or exceeding the Gothiatek standard

- Buy it fresh from a retailer who refrigerates the product

- Use snus that comes in the individual serving pouches or sachets

- Place the snus under your upper lip, toward the front of your mouth.

In the USA, moist snuff is placed between the cheek and gums in the lower rear of the mouth. Swedes have very low needs to expectorate compared to US snuff dippers. It is unknown if there are toxicological consequences from the excess salivation and increased swallowing of tobacco juice in the USA. Because of the lack of spitting, few people will know you are using snus. You should not care that snus has a different taste and mouth placement than US snuff: you are switching to snus from cigarettes, not US snuff.

4. Next try medicinal nicotine. Try to switch to cleaner forms of nicotine when you feel able.

5. Next stop using any nicotine if you can. But you should keep using medicinal nicotine, or even snus, as long as you need to, to keep you from smoking.

If you learn that your lawmaker is an inveterate smoker, please consider treating him as you would your brother.

\section{Authors' affiliations}

L T Kozlowski, R J O'Connor, B Quinio Edwards, Department of Biobehavioral Health, The Pennsylvania State University, Pennsylvania, USA

Correspondence to: Lynn T Kozlowski, PhD, Department of Biobehavioral Health, Penn State, 315 East Health and Human Development, University Park, PA 16802, USA; Itk1@psu.edu

\section{REFERENCES}

1 Foulds J, Ramstrom L, Burke M, et al. Effect of smokeless tobacco (snus) on smoking and public health in Sweden. Tobacco Control 2003; 12:349-59.

2 Bates C, Fagerstrom K, Jarvis MJ, et al. European Union policy on smokeless tobacco: a statement in favour of evidence based regulation for public health. Tobacco Control 2003; 12:360-7.

3 Dow Jones Business News. Talks break down of bill giving FDA cigarette authority. http://story.news.yahoo.com/news? tmpl = story\&u=/dowjones/ 20031002/bs_dowjones/200310020446000194 [Accessed 3 October 2003].

4 Hilts PJ. Protecting America's health: The FDA, business, and one hundred years of regulation. New York: Alfred A Knopf, 2003.

5 Tomar SL. Is use of smokeless tobacco a risk factor for cigarette smoking? The U.S. experience. Nicotine and Tobacco Research 2003;5:561-70.

6 O'Connor RJ, Kozlowski LT, Flaherty BP, et al. Most smokeless tobacco use does not cause cigarette smoking: results from the 2000 National Household Survey on Drug Abuse. Addictive Behaviors, (in press).

7 O'Connor RJ, Flaherty BP, Edwards BQ, et al. Regular smokeless tobacco use is not a reliable predictor of smoking onset when psychosocial predictors are included in the model. Nicotine and Tobacco Research 2003;5:535-44.

8 National Clearinghouse for Alcohol and Drug Information. Tips for teens: the truth about tobacco. http://www.health.org/govpubs/PHD633/ [Accessed 3 October 2003].

9 Philip Morris, USA. Health issues-Cigarette smoking and disease. http:// www.philipmorrisusa.com/health_issues/

cigarette_smoking_and_disease.asp [Accessed 3 October 2003].

10 Kozlowski LT. First, tell the truth: a dialogue on human rights, deception, and the use of smokeless tobacco as a substitute for cigarettes. Tobacco Control 2003;12:34-6

11 Kozlowski LT. Harm reduction, public health and human rights: smokers have a right to be informed of significant harm reduction options. Nicotine and Tobacco Research 2002;4(suppl 2):S55-60.

12 Kozlowski LT, O'Connor RJ. Apply federal research rules on deception to misleading health information: An example on smokeless tobacco and cigarettes. Public Health Reports 2003;118:187-92.

13 Kozlowski LT, Strasser AA, Giovino GA, et al. Applying the risk/use equilibrium: use medicinal nicotine now for harm reduction. Tobacco Control $2001 ; 10: 201-03$.

14 Mann JM. Medicine and public health, ethics, and human rights. In: Mann J, Gruskin S, Grodin M, Annas G, eds. Health and human rights. New York: Routlidge, 1999:7-20.

15 Stratton K, Shetty P, Wallace R, et al, eds. Clearing the smoke: assessing the science base for tobacco harm reduction. Washington DC: Institute of Medicine, National Academy Press, 2001.

16 Philip Morris, USA. Written statement of PM USA CEO Mike Szymanczyk to the Senate Health, Education, Labor and Pensions Committee Health Issues. http://www.philipmorrisusa.com/downloads/policies_practices/ legislation_regualtion/pdf/full_statement_aymanczyk.pdf [Accessed 3 October 2003]. 